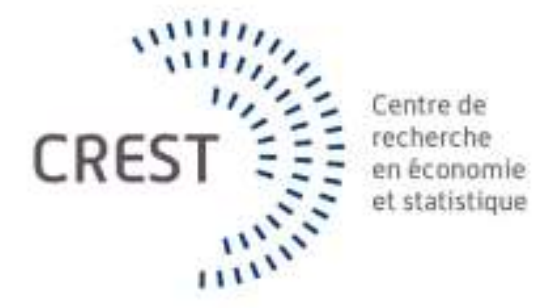

Série des Documents de Travail

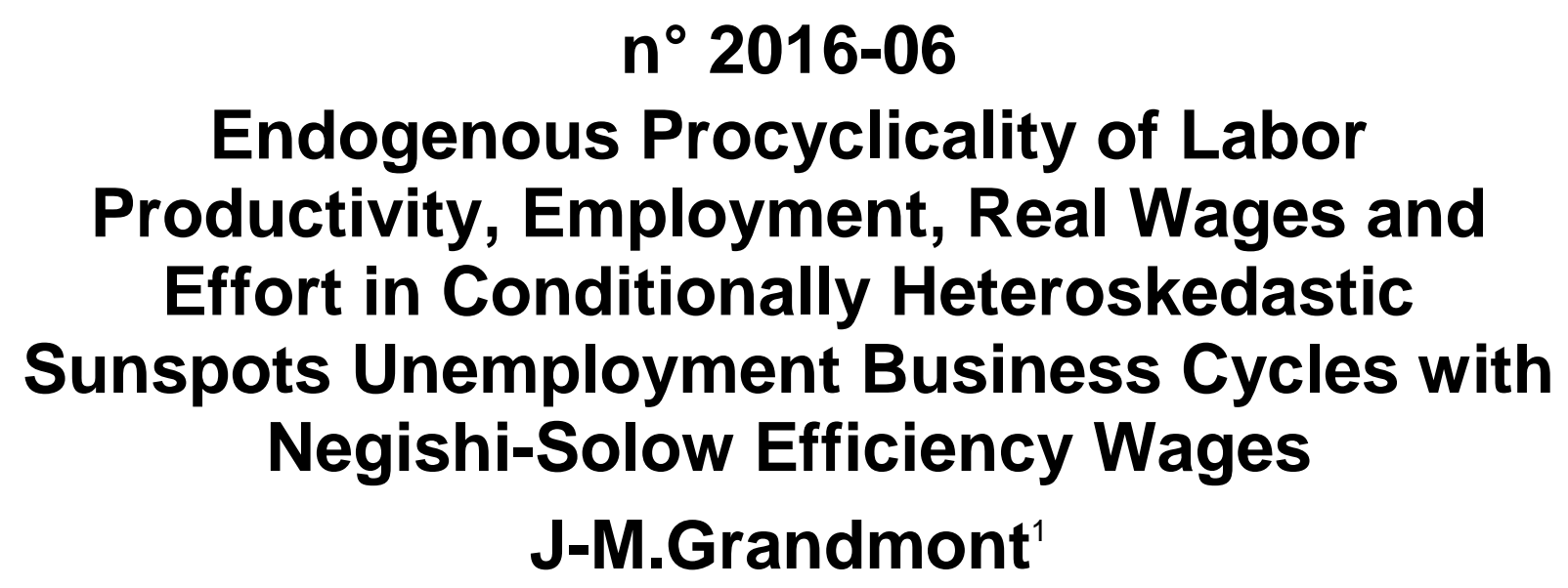

Les documents de travail ne reflètent pas la position du CREST et n'engagent que leurs auteurs. Working papers do not reflect the position of CREST but only the views of the authors.

${ }^{1}$ ICEF, Department of Economics, University Ca' Foscari di Venezia at San Giobbe, Italy, CREST (EXCESS, UMR CNRS 9194), Paris and RIEB fellow, University of Kobe, Japan. E-mail: JeanMichel.Grandmont@ensae.fr 


\title{
Endogenous Procyclicality of Labor Productivity, Employment, Real Wages and Effort in Conditionally Heteroskedastic Sunspots Unemployment Business Cycles with Negishi-Solow Efficiency Wages*
}

\author{
Jean-Michel Grandmont ${ }^{(1)}$
}

March 2016

${ }^{*}$ Early versions of parts of this work have been presented in various venues (Graig Hiemstra Memorial Lecture, Annual SNDE Symposium, ENSAE, Paris ; Portuguese Economics Journal Annual Meeting, Plenary Lecture, Evora, Portugal; Augustin Cournot Doctoral Days Lecture, Strasbourg ; Micro/Macroeconomics of the Labor Market International Meeting, Keynote Lecture, Cergy-Pontoise University, France). And in various international conferences and seminars : at the universities of Tokyo, of Kyoto and of Kobe in Japan; at the university of Leeds, UK; at the Center for Nonlinear Dynamics in Economics and Finance (CeNDEF) in Amsterdam; at GREQAM in Marseille and at the Center for Advanced Studies in Moscow. I am grateful for the comments of the participants of these conferences and to the members of CREST Macroeconomics seminar, and particularly to Frédérique Bec, Xavier d'Haultfoeuille, Guy Laroque, Etienne Lehmann, Jean-Michel Zakoian for helpful suggestions. I am also very grateful to Fanda TRAORE for her efficient typing. As usual, I am sole responsible for any remaining shortcomings of the paper.

${ }^{1}$ ICEF, Department of Economics, University Ca' Foscari di Venezia at San Giobbe, Italy, CREST (EXCESS, UMR CNRS 9194), Paris and RIEB fellow, University of Kobe, Japan. 


\begin{abstract}
This work introduces a new mechanism that is able to generate procyclical comovements of aggregate labor productivity, employment and real wages, through endogenous variations of workers' effort, in a simple model involving structural unemployment, efficiency wages, financial market imperfections and expectations driven conditionally heteroskedastic sunspots business cycles, near a locally indeterminate steady state. Owing to imperfect effort monitoring, workers' effort level equates their disutility of effort to their expected utility gain of not shirking, in terms of their earned real income, and of the resulting anticipated random consumption. A positive current (consumption) sunspot shock generates a countercyclical uncertainty shock, i.e. a drecrease of the anticipated sunspot volatility, and makes risk averse workers more willing to provide "precautionary effort" by increasing their expected utility gain of not shirking. If workers' relative prudence is small and decreasing fast near the steady state, profit maximizing firms' choice of efficiency wage contracts generates significant endogenous procyclical variations of effort and employment, in particular when the capital-efficient labor elasticity of substitution is smaller than 1.
\end{abstract}

Keywords : efficiency wages, unemployment, expectation driven business cycles, conditionally heteroskedastic sunspots, countercyclical uncertainty shocks, prudence, procyclical labor effort and productivity.

JEL classification : E00, E24, E32, J41.

\title{
1 Introduction
}

The basic motivation for the introduction of technology shocks in real business cycles (RBC) macroeconomic models was essentially to be able to generate more or less pronounced procyclical comovements of labor productivity, output, employment and real wages. With a standard neoclassical constant returns to scale aggregate production function $y_{t}=A F\left(k_{t-1}, l_{t}\right)$, where $y_{t}$ is output, $k_{t-1}$ the initial capital stock and $l_{t}$ labor supply, aggregate labor productivity as well as real wages are bound to be strongly countercyclical since $A F\left(k_{t-1}, l_{t}\right) / l_{t}$ and $A F_{l}^{\prime}\left(k_{t-1}, l_{t}\right)$ must go down when $l_{t}$ goes up. By contrast, these variables are empirically more or less procyclical, with employment (hours), output, being significantly more variable than observed 
labor productivity, while evidence on real wages seems to be more ambiguous, as they may be strongly or only mildly procyclical, and in some cases actually acyclical or even a little countercyclical (see e.g. Basu et al. (2001), Bils et al. (2001), Messina et al. (2009), Solon et al. (1994), Uhlig et al. (1996), Uhlig (2004), Verdugo (2016)). The way out in RBC models has been to postulate exogenous (unexplained) stochastic shocks to either the global productivity parameter $A_{t}$ or to analogous technological parameters characterizing the input (capital and/or labor) productivities in the aggregate production function $F$.

The alternative strategy chosen here is to take into account the fact that the labor input that enters the productive process is in the actual world a mixture of "hours" worked and of "effort". Specially, "efficient labor" is viewed as $l_{t}=n_{t} x_{t}$, where $n_{t}$ is the number of labor units employed ("hours") and $x_{t}$ is "effort" that in endogenously supplied by workers. The issue is then whether stochastic variations of the workers' effort $x_{t}$ can generate empirically plausible comovements of labor productivity $\alpha_{t}=y_{t} / n_{t}$, employment $n_{t}$ ("hours"), real wages, output. We also focus on the apparently relevant configuration where such fluctuations are driven by endogenous self-fulfilling expectations (sunspot) shocks near a locally indeterminate steady state, rather than by exogenous shocks to fundamentals. Finally, we incorporate structural persistent unvoluntary unemployment in the picture by building on the insightful efficiency wage arguments introduced long ago by Negishi (1979) and Solow (1979) (see also Yellen (1984)). The basic observation here is that in order to show convincingly that Keynesian unemployment can persist, it is not enough to claim that employed workers would resist wage cuts, e.g. through unions negotiations. One must explain why firms themselves are unwilling to cut down wages or hire unemployed workers at a lower wage. The core efficiency wage argument is, in a nutshell, that workers' effort supply (here $\left.x_{t}\right)$ is bound to depend on real or nominal wages, so that firms' profit maximization should lead them to choose persistently high real efficiency wage contracts, explaining indeed structurally persistent unvoluntary unemployment. Firms empirical surveys evidence seems to confirm the strong presence of such a mechanism in their wage setting and management behavior (Bewley (1999), Campbell et al. (1997), Stiglitz (1986)). There has been accordingly a significant literature on the incidence of efficiency wages on the dynamics of business cycles, but it has focused essentially on a RBC methodology, i.e. on fluctuations generated by shocks to fundamentals (Collard et al. (2000), 
Danthine et al. (1990, 2006), Uhlig (2004), Uhlig et al. (1996)). On the other hand, there has been quite a few recent studies of the dynamic prperties of expectations sunspots driven business fluctuations in the presence of unemployment, but they have essentially considered the case where wages are set through negotiations with labor unions (Dos Santos Ferreira (2015), Dufourt et al. $(2008,2009,2013))$. The present work seems to be the first to analyze the cyclical dynamical macroeconomic properties of expectations driven sunspot business fluctuations, in the presence of persistent unemployment based on explicit efficiency wage contracts arguments.

Specifically, we consider variable effort and efficiency wages as previously introduced in Grandmont (2008) in a standard finance constrained economy, as in Woodford (1986) and Grandmont et al. (1998), with a competitive market for output, two assets (capital and money) and heterogeneous households. At a deterministic steady state and nearby, "capitalists" hold capital as a positive interest bearing asset, and no money, which does not. "Workers", who are more impatient and face a finance (cash in advance) constraint, hold money and no capital. Efficiency wages are introduced in a way that is directly inspired from the "shirking" formulation of Coimbra (1999), Alexopoulos (2004), Nakajima (2006) and Aloi et al. (2006), following the early contribution of Shapiro et al. (1984). See also Danthine et al. (1990), Jullien et al. (1998). Efficiency wage contracts specify the wage and the required effort level. There is imperfect monitoring : an employed worker who "shirks" faces a positive probability of getting caught, in which case he or she is fired and gets unemployment insurance. Profit maximizing firms choose accordingly efficiency wage contracts involving reals wages high enough so as to induce employed workers to provide the requested effort level, i.e. not to "shirk". Hence the persistent occurrence of real wage downward "rigidities" and a resulting structural unemployment. To simplify matters, we abstract away from any additional "frictional" labor market imperfections such as matching or search.

It was shown in Grandmont (2008) that the deterministic dynamics of such an economy is bound to lead to a locally indeterminate steady state under a wide range of empirically relevant configurations. What we do here is to analyze the dynamical cyclical properties of stochastic sunspot equilibria near such a steady state. We first make precise the conditions needed to mae the dynamics of the economy, in particular of the firms' profit maximizing choice of efficiency wage contracts, well defined in such a stochastic context (section 
2.1). We show next how to construct, and prove the existence of, stochastic sunspot equilibria near a locally indeterminate steady state by adapting the methods and the results of Grandmont et al. (1998) (section 2.2). We then show that endogenous procyclical variations of workers' effort (here $x_{t}$ ) are indeed able to generate a range of more or less significant procyclical comovements of aggregate labor productivity (here $y_{t} / n_{t}$ ), employment $n_{t}$ ("hours"), or real wages, that is wide enough to fit empirical observations, in particular in the empirically plausible case where the capital-efficient labor elasticity of substitution is smaller than 1 (see Chirinko (2008)) (section 3.1.). We show finally (section 3.2) that conditionally heteroskedastic sunspot shocks to the workers' consumption process do generate procyclical effort movements under natural conditions on their attitudes toward risk. The key observation there is that the worker" "non-shirking schedule" determines at any time their effort level by equating their disutility of effort to their expected utility gain of "not-shirking", expressed in terms of the wage or unemployment insurance received, and thus of their ensuing anticipated random consumption. Effort is thus similar to "precautionary saving" in the sense that it enables workers to cope with the uncertainty of their future consumption, in the spirit of the early contributions of Leland (1968), Kimball (1990). If a positive current (workers' consumption) sunspot shock generates a countercyclical uncertainty shock, i.e. a decrease of the anticipated sunspot volatility, then it increases risk averse workers' expected utility gain of "not-shirking" for a given effort level, and thus makes them more willing to provide "precautionary effort" (as in Rothshild et al. (1970)). What we show here is that when consumption sunspot shocks are conditionally heteroskedastic as above, and if the workers' relative prudence is smaller than 2 and decreasing fast near the steady state, the firms' profit maximizing choice of efficiency wage contracts under the workers' non-shirking schedule is indeed able to generate the significant procyclical variations of effort we were looking for.

The "real" mechanism put forward here is based on an analogy of workers' effort with precautionary savings in the face of an uncertain future that seems highly plausible. Beyond the voluntarily oversimplified structure of the model that makes it unfit to full fledged empirical applications (e.g. nominal variables behave badly, i.e. countercyclically, as in any cash in advance model with a constant money stock), the real mechanism linking conditionally heteroskedatic sunspot consumption shocks to procyclical "precautionary effort" seems to be empirically quite plausible. Indeed, while the stochastic nature 
of the consumption process has been recognized for long (Hall (1978)), conditional heteroskedasticity of uncertainty or volatility shocks seems to get increasing theoretical and empirical attention. It has been long viewed as strongly empirically relevant in the field of finance and the analysis of asset prices and stock returns (Francq et al. (2010), Nelson (1991)). Recent findings that appear to uncover links between the stochastic properties of consumption, countercyclical macroeconomic uncertainty shocks and conditionally heteroskedastic financial shocks (Boguth et al. (2013), Bloom et al. (2014), Tedongap (2016), Wang (2006)), do suggest that investigating further theoretically and empirically the real mechanism presented in this work should be a fruitful avenue for future research.

\section{Stochastic expectations driven unemploy- ment business cycles}

We define and characterize in this section stationary stochastic sunspot equilibria near a deterministic steady sate of the simple economy introduced in Grandmont (2008), that involves efficiency wages in a dynamical macroeconomic model with heterogeneous agents and financial constraints as in Woodford (1986) and Grandmont et al. (1998).

\subsection{Agents behavior}

There are three types of agents : capitalists, workers and firms.

\section{Capital holders}

There is a continuum of identical small agents, of total size normalized to 1 , whose incomes are essentially generated by the returns of holding physical capital. To simplify matters, one considers the limit case where these agents do not work, and are thus called "capitalists". They are further assumed to maximize expected discounted intertemporal utility of consumption $c_{t+j, c}$ of the Cobb-Douglas type $E_{t}\left[\sum_{j=1}^{\infty}\left(\beta_{c}\right)^{j} \log c_{t+j, c}\right]$, where the discount factor satisfies $0<\beta_{c}<1$, given current and (possibly random) money prices of consumption $\left(p_{t+j}\right)$, and real gross rates of returns on capital $\left(R_{t+j}\right), j \geq 0$. There are two available assets : money, that does not bear interest, and capital. We assume rational expectations and focus on equilibria near a 
deterministic steady state satisfying $R_{t+1}=\bar{R}=1 / \beta_{c}>1=p_{t} / p_{t+1}$ for all $t$, so that $R_{t+j+1}>p_{t+j} / p_{t+j+1}$ will hold along deterministic or stochastic equilibria nearby for all $t, j$. Money is thus dominated as an asset along such equilibria and capitalists choose accordingly to hold capital only, leading to budget constraints of the form $c_{t c}+k_{t c}=R_{t} k_{t-1, c}$ in every period $t$ and to optimal consumption and capital investment plans given by

$$
c_{t c}=\left(1-\beta_{c}\right) R_{t} k_{t-1, c}, \quad k_{t c}=\beta_{c} R_{t} k_{t-1, c} .
$$

Workers

There is another continuum, also normalized to 1, of small identical agents, called "workers". Each individual worker supplies one unit of labor time, but effort supply $x_{t} \geq 0$ varies continuously and endogenously, while a worker's consumption is noted $c_{t w} \geq 0$. Instantaneous utility of consumption is noted $U\left(c_{t w}\right)$ and disutility of effort $V\left(x_{t}\right)$. Workers are assumed to maximize expected discounted utility over an infinite horizon, with a discount factor $0<\beta_{w}<1$.

To simplify matters, we assume that there is also a continuum of isolated identical local labor markets with a single firm dealing in each such local market and that workers are uniformly spread over them. This is in order to abstract away from the complexities involved in possible wage competition among firms or in possible workers migration ("search") accross local labor markets. Firms' maximizing profit behavior (to be described precisely shortly) will result in an efficiency wage contract $\left(w_{t}, x_{t}\right)$ specifying the nominal wage $w_{t}>0$ paid to an employed worker, under the requirement that the effort level $x_{t}>0$ is to be provided. Firms' behavior will generate also a demand $n_{t}>0$ of labor units. We focus here on unemployment, so at date $t$, the proportion $0<n_{t}<1$ of individual workers is offered the efficiency wage contract $\left(w_{t}, x_{t}\right)$. As we shall see, such a contract will be designed to induce the workers to make indeed the requested effort level ("incentive compatibility") : no worker will turn down the job offer, so that in any period there are $0<n_{t}<1$ workers employed and $0<1-n_{t}<1$ unvoluntarily unemployed. There is unemployment insurance, so employed workers are paid the nominal wage $w_{t}>0$, while unemployed workers get the income $0<\nu w_{t}<w_{t}$, the rate of compensation $0<\nu<1$ being constant and known by all agents. To simplify matters, it is assumed that unemployment insurance is funded by taxing the incomes of employed and unemployed workers at the uniform 
rate $0<1-d_{t}<1$. Then by definition, what is taxed away from employed workers is equal to the disposable income of unemployed workers, that is $\left(1-d_{t}\right) n_{t} w_{t}=\left(1-n_{t}\right) d_{t} \nu w_{t}$, which determines the rate $d_{t}$ from the wage rate, the insurance rate and employment $\left(w_{t}, \nu, n_{t}\right)$. An important simplifying feature of this approach is that the total amount of after tax income gotten at $t$ by all, employed and unemployed, workers, must be equal to the initial pre-taxes wage bill $n_{t} w_{t}>0$.

We focus on intertemporal stochastic equilibria near a deterministic steady state, along which stationary consumptions of employed and unemployed workers are noted $\bar{c}_{w}>0$ and $\nu \bar{c}_{w}>0$. We assume throughout

$$
U^{\prime}\left(\nu \bar{c}_{w}\right)>U^{\prime}\left(c_{w}\right)>\beta_{w}\left[\bar{R} U^{\prime}\left(\nu \bar{c}_{w}\right)\right]>\beta_{w}\left[\bar{R} U^{\prime}\left(\bar{c}_{w}\right)\right]
$$

where the steady state real gross rate of return of capital satisfies $\bar{R}=R_{t}=$ $1 / \beta_{c}$ for all $t$. These inequalities will hold whenever $a$ ) workers discount the future much more than capitalists, $0<\beta_{w}<\beta_{c}<1$, b) the unemployment insurance rate $\nu$ is relatively close to 1 , and $c$ ) workers marginal utility for consumption $U^{\prime}(c)$ does not decrease too fast. Condition (2) implies that for every possibly random consumption path near that steady state one has $U^{\prime}\left(c_{t w}\right)>\beta_{w} E_{t}\left[R_{t+1} U^{\prime}\left(c_{t+1, w}\right)\right]$ : a worker's marginal utility cost of investing at $t$ in one unit of capital exceeds its marginal expected utility gain, and this, no matter which current or expected employment state for this worker. One gets accordingly the standard conclusion that the more impatient agents, i.e. workers here, save by holding cash and no capital, while the situation is reversed for capitalists.

It is further assumed, here as in Woodford (1986) or Grandmont et al. (1998), that workers are subject to a finance constraint stating that they will get their disposable money wage or insurance income in cash at the end of the period but cannot borrow against it. Such a cash-in-advance constraint is binding at a deterministic steady state and thus nearby. Workers' behavior will display accordingly a simple two-periods overlapping generations structure : "young" workers do keep in period $t$ their current disposable income in the form of cash balances, in order to spend these to consume at time $t+1$, when "old". We assume a constant total money stock $M>0$, so that in equilibrium.

$$
\frac{M}{p_{t}}=n_{t} \omega_{t} \quad \text { and } \quad \frac{M}{p_{t+1}}=n_{t} c_{t+1, w}+\left(1-n_{t}\right) \nu c_{t+1, w}
$$


where $\omega_{t}=w_{t} / p_{t}$ is the real wage.

\section{Firms}

There is a continuum (again, normalized to 1) of identical small firms. Each firm combines at $t$ the services of initial capital $k_{t-1} \geq 0$ and "efficient" labor $l_{t}=n_{t} x_{t} \geq 0$ to produce output according to the constant returns to scale production function $y_{t}=A F\left(k_{t-1}, l_{t}\right) \geq 0$. For $l>0$, the reduced production function $y / l=A f(a)=A F(a, 1)$ is assumed to satisfy the standard condition:

(2.a) The reduced production function $y / l=A f(a)=A F(a, 1)$ is a smooth function of the capital-efficient labor ratio $a=k / l \geq 0$, with $f(0)=0$ and $f^{\prime}(a)>0, f^{\prime \prime}(a)<0$ for $a>0$. The marginal productivity of capital $A \rho(a)=A f^{\prime}(a)$ decreases from $+\infty$ to 0 , whereas the marginal productivity of efficient labor $A \omega(a)=A\left(f(a)-a f^{\prime}(a)\right)$ increases from 0 to $+\infty$, when a goes up from 0 to $+\infty$.

Firms seek to maximize their real profit

$$
A F\left(k_{t-1}, l_{t}\right)-\frac{\omega_{t}}{x_{t}} l_{t}-\rho_{t} k_{t-1}
$$

Given the real rental rate of capital services $\rho_{t}>0$ and the real wage per unit of effort $\omega_{t} / x_{t}>0$, a firm's optimum $k_{t-1}>0, l_{t}>0$ must satisfy the first order conditions.

$$
\rho_{t}=A \rho\left(a_{t}\right)>0 \text { and } \omega_{t} / x_{t}=A \omega\left(a_{t}\right)>0 .
$$

Capital stock is assumed to depreciate at the constant rate $0<\delta<1$. The real gross rate of return on capital $R_{t}$ is thus equal to $R\left(a_{t}\right)=A \rho\left(a_{t}\right)+1-\delta$.

Finally, profit maximization makes firms seek to design an efficiency wage contract $\left(w_{t}, x_{t}\right)$ that in effect minimizes the real cost of efficient labor $\omega_{t} / x_{t}$, under the constraint that it should maintain the workers' incentive to provide actually the effort level $x_{t}$.

\section{Efficiency wages contracts}

The set up considered here, as in Grandmont (2008), is of the "noshirking" variety, in the spirit of the early contribution of Shapiro and Stiglitz (1984). There is imperfect effort monitoring : a worker hired at $t$ under the 
contract $\left(w_{t}, x_{t}\right)$ who shirks, i.e. provides no effort, faces the probability $0<\theta<1$ to be caught. A non-shirking employed worker gets the after tax wage income $d_{t} \omega_{t} p_{t}$, which he keeps in cash in order to spend it on consumption next period $c_{t+1, w}=d_{t} \omega_{t} p_{t} / p_{t+1}$. An employed worker who is caught shirking is fired and receives the after tax unemployment insurance $\nu d_{t} \omega_{t} p_{t}$, leading to a consumption one period later equal to $c_{t+1, w}^{u}=\nu c_{t+1, w}$. Effort involves a disutility $V(x)$, while consumption generates utility $U(c)$. Workers will have no incentive to shirk if the expected utility gain of not shirking outweights the disutility of effort :

$$
V\left(x_{t}\right)-V(0) \leq \theta E_{t}\left[U\left(c_{t+1, w}\right)-U\left(\nu c_{t+1, w}\right)\right] \text { where } c_{t+1, w}=d_{t} \omega_{t} p_{t} / p_{t+1}
$$

In period $t$, each individual small firm takes as given current information about $d_{t}, p_{t}$ and the (rational) anticipation of the future price $p_{t+1}$, hence in particular of the possibly random sunspot market perturbation $\varepsilon_{t+1}=$ $\left[\left(1 / p_{t+1}\right)-E_{t}\left(1 / p_{t+1}\right)\right] / E_{t}\left(1 / p_{t+1}\right)$, assumed to be small with $E_{t}\left(\varepsilon_{t+1}\right)=0$. A firm's offer of a wage $w_{t}$ (or equivalently of a real wage $\omega_{t}=w_{t} / p_{t}$ ) affects then its workers' consumption essentially through the expected mean consumption $\bar{c}_{t+1, w}=E_{t}\left(c_{t+1, w}\right)=d_{t} \omega_{t} p_{t} E_{t}\left(1 / p_{t+1}\right)$, actual consumption being $c_{t+1, w}=$ $\bar{c}_{t+1, w}\left(1+\varepsilon_{t+1}\right)$. As the non-shirking condition (5) is bound to be binding at the optimum choice, this leads to

Lemma 1. Given the distribution $\tilde{\varepsilon}_{t+1}$ of random (sunspots) market perturbations $\left.\varepsilon_{t+1}=\left[\left(1 / p_{t+1}\right)-E_{t}\left(1 / p_{t+1}\right)\right] / E_{t}\left(1 / p_{t+1}\right)\right]$, with arbitrarily small support $-a \leq \varepsilon_{t+1} \leq b$ and $E_{t}\left(\varepsilon_{t+1}\right)=0$, each firm chooses an efficiency wage contract at $t$ so as to maximize effort $x_{t} \geq 0$ per unit of expected mean consumption $\bar{c}_{t+1, w}=E_{t}\left(c_{t+1, w}\right)$, i.e. $x_{t} / \bar{c}_{t+1, w}$, under the non-shirking schedule $(N S S)$

$$
V\left(x_{t}\right)-V(0)=\Phi\left(\bar{c}_{t+1, w} ; \tilde{\varepsilon}_{t+1}\right)
$$

where

$$
\Phi\left(\bar{c}_{t+1, w} ; \tilde{\varepsilon}_{t+1}\right)=E_{t}\left[\varphi\left(\bar{c}_{t+1, w}\left(1+\varepsilon_{t+1}\right)\right)\right] \text { with } \varphi(c)=\theta[U(c)-U(\nu c)] .
$$

The mechanisms underlying the workers' (non-)shirking behavior (6),(7) are strongly related to the curvatures of the functions involved. That is a) their aversion toward effort (curvature of $V(x)$ ) and $b$ ) their attitude toward 
risk (curvature of $U(c)$ ). The latter goes essentially through the degree of concavity of $\varphi(c)=\theta[U(c)-U(\nu c)]$, which stands for the expected utility gain of making the right effort while taking into account the risk of being caught, with probability $\theta$, if shirking, this risk being present even in the absence of sunspots shocks. In this respect, we shall assume throughout, as in Grandmont (2008) for the deterministic case $\varepsilon_{t+1} \equiv 0$

(2.b) Disutility of effort $V(x)$ is smooth for $0<x<\bar{x}$, where $\bar{x}$ is the maximum (possibly infinite) effort level, increasing and strictly convex, $V^{\prime}(x)>0, V^{\prime \prime}(x)>0$, with $V^{\prime}(x)$ going to $+\infty$ when $x$ tends to $\bar{x}$. There is a fixed cost of effort, $\lim _{x \rightarrow 0} V(x)=x_{0}>V(0)=0$.

(2.c) Utility of consumption $U(c)$ is snooth for $c \geq 0$, increasing and strictly concave, $U^{\prime}(c)>0, U^{\prime \prime}(c)<0$, with marginal utility $U^{\prime}(c)$ decreasing from $+\infty$ to 0 when consumption c goes up from 0 to $+\infty$. Utility for consumption displays not too large relative risk aversion, $R_{U}(c)=-c U^{\prime \prime}(x) / U^{\prime}(c)<$ 1 , or equivalently $c U^{\prime}(c)$ is increasing.

(2.d) The fixed cost of providing effort is positive but not too large, whereas the disutility of the maximum effort level $\bar{x}$ is high

$$
0<x_{0}<\lim _{c \rightarrow+\infty} \varphi(c)=\theta[U(c)-U(\nu c)]<\lim _{x \rightarrow \bar{x}} V(x)
$$

Assumption (2.c) implies that $\varphi(c)$ is increasing, and thus that the right hand side of the NSS (6) is also increasing in $\bar{c}_{t+1, w}$. Adding assumptions $(2 . b)$ and (2.d) ensures next that this NSS (6) determines the effort level $x_{t}$ as a function of expected mean consumption $\bar{c}_{t+1, w}$, given the distribution $\tilde{\varepsilon}_{t+1}$ of the random sunspots disturbance, $x_{t}=H\left(\bar{c}_{t+1, w} ; \tilde{\varepsilon}_{t+1}\right)$, where : 1) $\left.H\left(0 ; \tilde{\varepsilon}_{t+1}\right)=0,2\right) x_{t}$ is well defined whenever $\bar{c}_{t+1, w}>c_{t+1}^{0}$ where $c_{t+1}^{0}>$ 0 is the minimum expected mean consumption required to cover the fixed disutility cost of providing effort, i.e. $x_{0}=\Phi\left(c_{t+1}^{0} ; \tilde{\varepsilon}_{t+1}\right)$, in which case

$$
x_{t}=H\left(\bar{c}_{t+1, w} ; \tilde{\varepsilon}_{t+1}\right)=V^{-1}\left[\Phi\left(\bar{c}_{t+1, w} ; \tilde{\varepsilon}_{t+1}\right)\right]>0 \text { for } \bar{c}_{t+1, w}>c_{t+1}^{0}>0,
$$

and 3) $\inf _{c>c_{t+1}^{0}} H\left(\bar{c}_{t+1, w} ; \tilde{\varepsilon}_{t+1}\right)=0$.

Finally, workers' incentives to provide an effort level $x_{t}>0$ in the NSS $(6),(7)$ do bear similarities with the motives to invest in "precautionary 
savings" when facing risky future income. So we might expect that some measure of workers' attitudes toward risk such as "prudence" might play a role in the present framework as well. This is indeed the case in the following assumption (2.e), which ensures that $\varphi(c)$ is strictly concave, i.e. $c^{2} \varphi^{\prime \prime}(c)=\theta\left[c^{2} U^{\prime \prime}(c)-\nu^{2} c^{2} U^{\prime \prime}(\nu c)\right]<0$. This implies that $\Phi\left(\bar{c}_{t+1, w} ; \tilde{\varepsilon}_{t+1}\right)$ has the same property with respect to $\bar{c}_{t+1, w} \geq 0$, as well as $H\left(\bar{c}_{t+1, w} ; \tilde{\varepsilon}_{t+1}\right)=$ $V^{-1}\left[\Phi\left(\bar{c}_{t+1, w} ; \tilde{\varepsilon}_{t+1}\right]\right.$ for $\bar{c}_{t+1, w}>c_{t+1}^{0}$.

(2.e) $c U^{\prime}(c)$ is strictly concave (i.e. $-c^{2} U^{\prime \prime}(c)$ is increasing) or equivalently relative prudence is not too large, i.e. $P_{U}=-c U^{\prime \prime \prime}(c) / U^{\prime \prime}(c)<2$.

\section{Figure 1}

Under these assumptions, the non-shirking schedule (8) can be simply represented graphically as in Figure 1. It is then not difficult to verify that under these conditions, profit maximization, as specified in Lemma 1, generates consistently a unique efficiency wage contract at time $t$ (the proof of the analogous Proposition 1 in Grandmont (2008), Appendix II) for the deterministic case $\varepsilon_{t+1} \equiv 0$, applies to the case at hand with sunspots shocks with only marginal adaptations).

Proposition 1. Under assumptions (2.b), (2.c), (2.d), (2.e), given the distribution of anticipated small sunspots random perturbations $\varepsilon_{t+1}=$ $\left[\left(1 / p_{t+1}\right)-E_{t}\left(1 / p_{t+1}\right)\right] / E_{t}\left(1 / p_{t+1}\right)$, there is a unique profit maximizing efficiency wage contract that maximizes effort per unit of expected mean consumption $x_{t} / \bar{c}_{t+1, w}>0$ under the non-shirking conditions (6),(7). It is characterized by the first order condition

$$
x_{t} V^{\prime}\left(x_{t}\right)=\bar{c}_{t+1, w} \Phi_{c}^{\prime}\left(\bar{c}_{t+1, w} ; \tilde{\varepsilon}_{t+1}\right) .
$$

We shall assume throughout (2.b) to (2.e). In the case of a constant elasticity (CRRA) specification $U(c)=c^{1-\eta} /(1-\eta)$, where $\eta=R_{U}(c)=$ $P_{U}(c)-1$, assumptions $(2 . c)$ and (2.e) are satisfied whenever $0<\eta<1$. 


\subsection{Stationary stochastic sunspot unemployment equi- libria}

We characterize now how stationary stochastic sunspot unemployment equilibria are generated arbitrarily near a locally indeterminate deterministic steady state of this economy. All fundamental real characteristics of the system are constant over time. Expectations driven fluctuations are generated by endogenous sunspots shocks in every period to the agents' expectations about money prices of the good. These sunspots shocks are summarized by a stationary stochastic process, with arbitrarily small support, $\left\{\varepsilon_{t}=\left[\left(1 / p_{t}\right)-E_{t-1}\left(1 / p_{t}\right)\right] / E_{t-1}\left(1 / p_{t}\right)\right\}$ for all $t$. From Proposition 1 , this determines fully the dynamics of effort and expected mean consumption $\left(x_{t}, \bar{c}_{t+1, w}\right)$, and thus of employed workers' consumption through $c_{t+1, w}=\bar{c}_{t+1, w}\left(1+\varepsilon_{t+1}\right)$. To complete the description of the dynamics, one needs to look at the evolution of capital stocks $k$ and of the capital-efficient labor ratios $a=k / l$. Specifically,

Definition 1. Given a stationary stochastic process of sunspots shocks $\varepsilon_{t}=\left[\left(1 / p_{t}\right)-E_{t-1}\left(1 / p_{t}\right)\right] / E_{t-1}\left(1 / p_{t}\right)$ with arbitrarily small support, the $d y$ namics of the economy is described by

a) the stochastic process of effort levels $x_{t}>0$ and of employed workers expected mean consumption $\bar{c}_{t+1, w}=E_{t}\left(c_{t+1, w}\right)$, where $c_{t+1, w}=\bar{c}_{t+1, w}\left(1+\varepsilon_{t+1}\right)$, generated by firms' profit maximizing choice of efficiency wage contracts, as in Proposition 1,

b) the two-dimensional stochastic process of capital stocks $k_{t}$ and of capitalefficient labor ratios $a_{t}=k_{t-1} / l_{t}$ driven by

$$
\begin{gathered}
k_{t}=\beta_{c} R\left(a_{t}\right) k_{t-1} \quad \text { with } \quad R\left(a_{t}\right)=A \rho\left(a_{t}\right)+1-\delta \\
\frac{k_{t} A \omega\left(a_{t+1}\right)}{a_{t+1}}=g\left(\frac{k_{t-1}}{a_{t}} ; x_{t}, \bar{c}_{t+1, w}\right)\left(1+\varepsilon_{t+1}\right) \\
\text { where } \quad g\left(l_{t} ; x_{t}, \bar{c}_{t+1, w}\right)=\frac{l_{t}}{x_{t}} \bar{c}_{t+1, w}+\left(1-\frac{l_{t}}{x_{t}}\right) \nu \bar{c}_{t+1, w} .
\end{gathered}
$$

Indeed, (10) stand for the capital accumulation equation of capital holders (1), while (11), (12) are mere translations of the money market equilibrium 
relations (3). The left hand side of (11) being in fact $M / p_{t+1}=n_{t+1} \omega_{t+1}=$ $l_{t+1} \omega_{t+1} / x_{t+1}$ together with $l_{t+1}=k_{t} / a_{t+1}$ (by definition), and real wage per unit of effort being equal to $A \omega\left(a_{t+1}\right)$ from the firms' profit maximization (4). The right hand side of (11), (12) being simply the second part of (3), with $n_{t}=l_{t} / x_{t}$ and $c_{t+1, w}=\bar{c}_{t+1, w}\left(1+\varepsilon_{t+1}\right)$.

The deterministic dynamics of the economy is obtained when there are no sunspots shocks to expectations, $\varepsilon_{t} \equiv 0$ for all $t$. In such a case, from Proposition $1, x_{t}=x^{*}$ and $c_{t+1, w}=c^{*}$ are constant. The deterministic dynamics (10), (11), (12) reduces then to a two-dimensional deterministic difference equation $\left(k_{t}, a_{t+1}\right)=G\left(k_{t-1}, a_{t}\right)$. Geometrically, stochastic sunspots equilibria are the result of the composition of this deterministic dynamics in the plane $(k, a)$, followed by a "vertical" random perturbation of the variable $a_{t+1}$, that results from the addition of the sunspot shock $\varepsilon_{t+1}$ in (11), together with the small stochastic perturbation of $\left(x^{*}, c^{*}\right)$ to $\left(x_{t}, \bar{c}_{t+1, w}\right)$ resulting from the impact of sunspots shocks on efficiency wage contracts as in Proposition 1. The constructive analysis of stationary stochastic sunspots equilibria arbitrarily near locally (in)determinate deterministic equilibria presented in Grandmont et al. (1998, Section 3) applies therefore formally here. In particular,

Proposition 2. Consider a locally indeterminate deterministic steady state with $\varepsilon_{t} \equiv 0, x_{t}=x^{*}>0, c_{t+1, w}=c^{*}>0, k_{t}=\bar{k}>0, a_{t}=\bar{a}>0$ for all $t$, with unemployment $\bar{n}<1$. Then for any arbitrarily small neighborhood of that steady state, one can construct infinitely many stationary sunspot equilibria as in Definition 1, that stay in that neighborhood for all t, by choosing an arbitrary stationary stochastic process of sunspots shocks $\left\{\varepsilon_{t}\right\}$, and scaling it down appropriately.

This follows by applying the arguments of Proposition 3.1 and Theorem 3.2 in Grandmont et al. (1998).

\section{Procyclicality of labor productivity, real wa- ge, employment and effort, and heteroskedas- tic sunspots}

We derive in this section conditions under which labor productivity $y_{t} / n_{t}$, employment $n_{t}$, real wages $\omega_{t}$ are procyclical along stationary stochastic sunspot 
equilibria in this economy. If effort were constant, $x_{t}=x^{*}$ for all $t$, as would be the case in a standard neoclassical model, efficient labor $l_{t}=n_{t} x^{*}$ would essentially coincide with employment. In such a case, labor productivity $\left.y_{t} / n_{t}=A f\left(a_{t}\right) x^{*}\right)$, real wages $\omega_{t}=A \omega\left(a_{t}\right) x^{*}$ are anticyclical. Clearly, to recover procyclicality of labor productivity $y_{t} / n_{t}=A f\left(a_{t}\right) x_{t}$, of real wages $\omega_{t}=A \omega\left(a_{t}\right) x_{t}$, without introducing exogenous shocks to the productivity parameter $A$, one needs effort $x_{t}$ itself to be variable and endogenously procyclical (Section 3.1). It is also clear from Proposition 1 that one needs non-vanishing stochastic sunspots shocks $\varepsilon_{t} \neq 0$ to be able to generate such a picture : in the case of the deterministic dynamics of the economy $\left(\varepsilon_{t} \equiv 0\right.$ for all $t$ ), effort and employed workers consumption are bound to stay constant, $x_{t}=x^{*}, c_{t w}=c^{*}$ for all $t$. By contrast, in the case of non-vanishing sunspots $\left(\varepsilon_{t} \neq 0\right)$, procyclicality of effort $x_{t}$ should obtain if the incentive of employed workers to provide effort is stimulated when $\varepsilon_{t}$ goes up today. From (6),(7), in Lemma 1, one may expect that this will occur, under some conditions on workers' attitudes toward risk and aversions toward effort, if a higher current sunspot shock $\varepsilon_{t}$ generates an anticipation of a less risky future sunspot shock $\varepsilon_{t+1}$, since then the expected utility of not shirking $E_{t}\left[\varphi\left(c_{t+1, w}\right)\right]$ gets larger as illustrated in Fig.1 (Section 3.2).

\subsection{Comovements of productivity, employment, real wages and variable effort}

We assume throughout conditions $(2 . a),(2 . b),(2 . c),(2 . d),(2 . e)$, and consider a stationary stochastic sunspot equilibrium near a locally indeterminate deterministic steady state $x_{t}=x^{*}>0, c_{t w}=c^{*}>0, k_{t}=\bar{k}>0, a_{t}=\bar{a}>0$ for all $t$. Such a sunspot equilibrium is constructed, as in Proposition 2 and Definition 1, from a given stationary stochastic process of small sunspots shocks $\left\{\varepsilon_{t}\right\}$. We look at period $t$ and analyze the consequences of a small positive shock $d \varepsilon_{t}>0$, given history up to time $t-1$. This sunspot shock affects directly workers current consumption $c_{t w}=\bar{c}_{t w}\left(1+\varepsilon_{t}\right)$, with $\bar{c}_{t w}=E_{t-1}\left[c_{t w}\right]$

(and $\nu c_{t w}$ for those who where unemployed at $t-1$ ), so that $\frac{d c_{t w}}{c_{t w}}=\frac{d \varepsilon_{t}}{1+\varepsilon_{t}}$. From the money market equilibrium condition (11) adapted to period $t$,

$$
\frac{k_{t-1} A \omega\left(a_{t}\right)}{a_{t}}=n_{t} \omega_{t}=\left(n_{t-1}+\left(1-n_{t-1}\right) \nu\right) \bar{c}_{t w}\left(1+\varepsilon_{t}\right)
$$

it is clear that the impact of $d \varepsilon_{t}>0$ will rest significantly on the local 
response of the marginal productivity of efficient labor $A \omega(a)$ at the steady state and nearby. We recall the useful standard relations

$$
\varepsilon_{\omega}(a)=\frac{a \omega^{\prime}(a)}{\omega(a)}=\frac{s(a)}{\sigma(a)}, \quad \varepsilon_{\rho}(a)=\frac{a \rho^{\prime}(a)}{\rho(a)}=-\frac{1-s(a)}{\sigma(a)}
$$

where $s(a)=a f^{\prime}(a) / f(a)$ is the share of capital in total income and $\sigma(a)$ is the capital-efficient labor elasticity of substitution. We assume throughtout

$$
\text { (3.a) } \sigma(\bar{a})>s(\bar{a})
$$

at the deterministic steady state and thus nearby. From Grandmont (2008, Proposition 4) this is a necessary condition for local indeterminacy. It implies in particular that $\omega(a) / a$ is decreasing, so that in view of $(13)$, following the positive sunspot shock $d \varepsilon_{t}>0, a_{t}=k_{t-1} / l_{t}$ goes down

$$
\frac{d l_{t}}{l_{t}}=-\frac{d a_{t}}{a_{t}}=\frac{\sigma\left(a_{t}\right)}{\sigma\left(a_{t}\right)-s\left(a_{t}\right)} \frac{d \varepsilon_{t}}{1+\varepsilon_{t}}>0
$$

whereas output $y_{t}=A F\left(k_{t-1}, l_{t}\right)$ and capital $k_{t}=\beta_{c} R\left(a_{t}\right) k_{t-1}$ go up. On the other hand, as in any standard neoclassical model, efficient labor productivity $\alpha_{t}^{e}=y_{t} / l_{t}=A f\left(a_{t}\right)$ should go down. Here one will get that plain labor productivity $\alpha_{t}=y_{t} / n_{t}=A f\left(a_{t}\right) x_{t}$ becomes procyclical if effort $x_{t}$ itself is sufficiently procyclical. Similarly, in order to get real wages $\omega_{t}=A \omega\left(a_{t}\right) x_{t}$ to become procyclical, one needs also effort to be procyclical enough. By contrast, in order to get employment $n_{t}=l_{t} / x_{t}$ to be procyclical one needs that effort $x_{t}$ be not too much procyclical. Specifically, one gets easily by straight (log)differenciation :

Proposition 3. Consider a stationary stochastic sunspot equilibrium near a locally indeterminate deterministic steady state, driven by the process $\left\{\varepsilon_{t}\right\}$ of stationary stochastic sunspots shocks. Following a small increase $d \varepsilon_{t}>0$ of the sunspot shock in period $t$,

1) Labor productivity $\alpha_{t}=y_{t} / n_{t}=A f\left(a_{t}\right) x_{t}$ will be procyclical if effort $x_{t}$ increases sufficiently, i.e. $\frac{d \alpha_{t}}{\alpha_{t}}>0$ if and only if

$$
\frac{d x_{t}}{x_{t}}>-s\left(a_{t}\right) \frac{d a_{t}}{a_{t}}=\frac{s\left(a_{t}\right) \sigma\left(a_{t}\right)}{\sigma\left(a_{t}\right)-s\left(a_{t}\right)} \frac{d \varepsilon_{t}}{1+\varepsilon_{t}} .
$$


2) The real wage $\omega_{t}=A \omega\left(a_{t}\right) x_{t}$ will be procyclical if effort $x_{t}$ goes up sufficiently, i.e. $\frac{d \omega_{t}}{\omega_{t}}>0$ if and only if

$$
\frac{d x_{t}}{x_{t}}>-\frac{s\left(a_{t}\right)}{\sigma\left(a_{t}\right)} \frac{d a_{t}}{a_{t}}=\frac{s\left(a_{t}\right)}{\sigma\left(a_{t}\right)-s\left(a_{t}\right)} \frac{d \varepsilon_{t}}{1+\varepsilon_{t}} .
$$

3) Employment $n_{t}=l_{t} / x_{t}$ will be procyclical if effort $x_{t}$ does not increase too much, i.e. $\frac{d n_{t}}{n_{t}}>0$ if and only if

$$
\frac{d x_{t}}{x_{t}}<\frac{d l_{t}}{l_{t}}=\frac{\sigma\left(a_{t}\right)}{\sigma\left(a_{t}\right)-s\left(a_{t}\right)} \frac{d \varepsilon_{t}}{1+\varepsilon_{t}} .
$$

The above findings illustrate the potential relevance of introducing variable procyclical effort $x_{t}$ as a key factor toward explaining a few dynamic properties of observed macroeconomic variables corresponding to $\alpha_{t}, n_{t}, w_{t}$. Empirically, these are more or less procyclical, with employment $n_{t}$ being significantly more variable than observed labor productivity $\alpha_{t}=y_{t} / n_{t}$, whereas the evidence on real wage $\omega_{t}$ seems to be mixed, as it may be only mildly procyclical and in some cases actually acyclical or even mildly anticyclical (see e.g. Basu et al. (2001), Bils et al. (2001), Messina et al. (2009), Solon et al. (1994), Uhlig et al. (1996), Verdugo (2016)). The difficulties to obtain such properties within standard neoclassical models or new-Keynesian models with nominal rigidities have been a significant motivation to rely on exogenous shocks to the global productivity parameter $A$ in standard RBC models. The following corollary demonstrates that one can indeed easily reproduce such empirical regularities through endogenous procyclical variations of effort $x_{t}$ in an efficiency wages model as considered here, in the empirically relevant case where the elasticity of capital-efficient labor substitution $\sigma$ is somewhat less than 1 (see Chirinko (2008)).

Corollary 1. Consider the benchmark configuration where the real wage $\omega_{t}$ is approximately acyclical at the steady state, i.e. $\frac{d x_{t}}{x_{t}} \simeq \frac{s}{\sigma-s} \frac{d \varepsilon_{t}}{1+\varepsilon_{t}}$, where $s$ and $\sigma$ stand for $s\left(a_{t}\right), \sigma\left(a_{t}\right)$ evaluated at the steady state. Employment $n_{t}$ varies then procyclically like the current sunspot consumption shock $\varepsilon_{t}$ while the covariation of labor productivity $\alpha_{t}=A f\left(a_{t}\right) x_{t}$ is given by

$$
\frac{d \varepsilon_{t}}{1+\varepsilon_{t}}=\frac{d c_{t w}}{c_{t w}}=\frac{d n_{t}}{n_{t}} \simeq \frac{\sigma-s}{s(1-\sigma)} \frac{d \alpha_{t}}{\alpha_{t}} .
$$


Labor productivity $\alpha_{t}$ is then procyclical when $s<\sigma<1$, with employment being significantly more variable than labor productivity when $\sigma$ is relatively close to 1 . With the income capital share set at $s=0.3$, one gets $d n_{t} / n_{t} \simeq$ $2.5 d \alpha_{t} / \alpha_{t}$ when $\sigma=0.6$, or $d n_{t} / n_{t} \simeq 8.3 d \alpha_{t} / \alpha_{t}$ when $\sigma=0.8$.

Mild procyclical (resp. countercyclical) variations of the real wage are then obtained from small increases (resp. decreases) of $d x_{t} / x_{t}$ from the above benchmark acyclical configuration.

\subsection{Conditionally heteroskedastic sunspots and pro- cyclical effort}

We study now the mechanisms than can generate a procyclical increase of effort $d x_{t}>0$ as a result of a positive sunspot consumption shock $d \varepsilon_{t}=$ $d c_{t w}>0$ at time $t$, as described in the previous section. From Proposition 1 , along the stationary sunspot equilibrium under consideration, the current effort level $x_{t}$ and employed workers' expected mean consumption $\bar{c}_{t+1, w}=$ $E_{t}\left[c_{t+1, w}\right]$ are determined by the anticipated distribution of the random future sunspot shock $\varepsilon_{t+1}$, through the firms' choices of an efficiency wage contract. Clearly, if the given sunspots shocks processes $\left\{\varepsilon_{t}\right\}$ were i.i.d., the resulting equilibrium sequence $\left(x_{t}, \bar{c}_{t+1, w}\right)$ would be deterministic and constant over time. To get procyclical effort variations, it is thus necessary that the current shock $\varepsilon_{t}$ affects the distribution of $\varepsilon_{t+1}$. Specifically, in view of the NSSS (8)

$$
V\left(x_{t}\right)-V(0)=E_{t}\left[\varphi\left(\bar{c}_{t+1, w}\left(1+\varepsilon_{t+1}\right)\right)\right],
$$

where the worker's expected utility of not shirking $\varphi(c)=\theta[U(c)-U(\nu c)]$ is strictly concave under assumption (2.e) (relative prudence $P_{U}(c)=$ $-c U^{\prime \prime \prime}(c) / U^{\prime \prime}(c)$ is low), we need that a current positive sunspot shock $d \varepsilon_{t}>0$ decreases the risk involved in future consumption $c_{t+1, w}=\bar{c}_{t+1, w}\left(1+\varepsilon_{t+1}\right)$ so as to increase the workers' incentives to provide effort (i.e. to make the right hand side of the NSS (16) to go up, as illustrated in Fig.1). We shall assume accordingly

(3.b) The stationary sunspot shocks process $\left\{\varepsilon_{t}\right\}$ is conditionally heteroskedastic : a positive increase of the current shock $\varepsilon_{t}$ make the vari-

ance of the future shock $v_{t+1}=E_{t}\left[\varepsilon_{t+1}^{2}\right]$ to decrease, i.e. $d \varepsilon_{t}>0$ implies $d v_{t+1}=d\left(E_{t}\left[\varepsilon_{t+1}^{2}\right]\right)<0$. 
Assumption (3.b) (heteroskedastic sunspots) and (2.e) (low relative prudence) do ensure that effort per unit of real wage, or of expected mean consumption $x_{t} / \bar{c}_{t+1, w}$, will be procyclical. Since current effort $x_{t}$ plays a role similar to "precautionary saving", that guarantees the expected mean consumption $\bar{c}_{t+1, w}$ and aims at coping with the risky future sunspot shock $\varepsilon_{t+1}$, one should expect that actual movements of $x_{t}$ and $\bar{c}_{t+1, w}$ will depend significantly on further properties of the workers' attitudes toward risk or effort, as they condition the curvatures of the NSS (16) in Fig. 1, and of the firms' FOC

$$
x_{t} V^{\prime}\left(x_{t}\right)=E_{t}\left[\bar{c}_{t+1, w}\left(1+\varepsilon_{t+1}\right) \varphi^{\prime}\left(\bar{c}_{t+1, w}\left(1+\varepsilon_{t+1}\right)\right)\right]
$$

As we are going to see shortly, in the constant elasticity specification of the workers' utility function $U(c)$, where relative prudence $P_{U}(c)$ is constant, effort $x_{t}$ is actually constant and determined independently of the sunspot distribution $\varepsilon_{t+1}$, while expected mean consumption $\bar{c}_{t+1, w}$ is countercyclical (Lemma 2). We show by contrast that effort is procyclical $\left(d x_{t}>0\right.$ as a result of a positive shock $\left.d \varepsilon_{t}>0\right)$ if relative prudence $P_{U}(c)$ is small and decreasing fast on an interval containing the steady state consumptions $c^{*}$ and $\nu c^{*}$. We also show that expected mean consumption $\bar{c}_{t+1, w}$ is procyclical in such a prudence configuration if the workers' relative degree of aversion to effort is small, while it may become countercyclical if it is large (Proposition $4)$. The strength of these comovements is larger, the larger of the degree of heteroskedasticity postulated in (3.b). We end up with an illustration by considering the HARA family for the workers' utility function (Corollary 2).

Lemma 2. In the constant elasticity (CRRA) case for the workers' utility, $U(c)=c^{1-\eta} /(1-\eta)$ with $0<\eta<1$, the optimum efficiency wage conditions (16), (17) reduce to

$$
(1-\eta)\left(V\left(x_{t}\right)-V(0)\right)=\theta\left(1-\nu^{1-\eta}\right) E_{t}\left[\left(\bar{c}_{t+1, w}\left(1+\varepsilon_{t+1}\right)\right)^{1-\eta}\right]=x_{t} V^{\prime}\left(x_{t}\right) .
$$

The resulting effort is constant and equal to the deterministic steady state effort level $x_{t}=x^{*}$ for all $t$. Expected mean consumption $\bar{c}_{t+1, w}$ is then countercyclical.

The proof follows immediately from expliciting the right hand sides of (16), (17), which become in fact identical in this particular specification. 
To deal with the relevant general case where relative prudence $P_{U}(c)$ is decreasing near the deterministic steady state, we proceed by considering the second order Taylor expansions of the dynamics (16), (17) of the efficiency wage contract $\left(x_{t}, \bar{c}_{t+1, w}\right)$ near that deterministic steady state, with respect to the small anticipated sunspot consumption shock $\varepsilon_{t+1}$. This makes apparent the impact of its variance $v_{t+1}=E_{t}\left[\left(\varepsilon_{t+1}^{2}\right)\right]$. To simplify the exposition, when there is no ambiguity, we use the notations $x=x_{t}, c=\bar{c}_{t+1, w}, v_{\varepsilon}=v_{t+1}$ :

$$
\begin{gathered}
V(x)-V(0) \simeq \varphi(c)+\frac{1}{2} c^{2} \varphi^{\prime \prime}(c) v_{\varepsilon}, \\
x V^{\prime}(x) \simeq c \varphi^{\prime}(c)+\left(c^{2} \varphi^{\prime \prime}(c)+\frac{1}{2} c^{3} \varphi^{\prime \prime \prime}(c)\right) v_{\varepsilon} .
\end{gathered}
$$

Proposition 4. Consider a positive current consumption shock $d \varepsilon_{t}>0$. It generates, under assumption (3.b), a decrease of the anticipated variance, $d v_{t+1}<0$.

1) The resulting effort level is procyclical, i.e. $d x_{t}>0$, if the workers' relative prudence $P_{U}(c)$ is low and decreasing fast

$$
\varepsilon_{P_{U}}(c)=c P_{U}^{\prime}(c) / P_{U}(c)<P_{U}(c)-2<0
$$

on a whole interval $\left(\gamma_{1}, \gamma_{2}\right)$ including the deterministic steady state consumptions $c^{*}$ and $\nu c^{*}$, and thus along the stationary stochastic sunspot equilibrium nearby. The larger the inequalities in (20), and the larger in absolute value the heteroscedasticity $d v_{t+1} / d \varepsilon_{t}<0$ in (3.b), the larger the procyclical variation $d x_{t} / d \varepsilon_{t}>0$.

2) Expected mean consumption is also procyclical, i.e. $d \bar{c}_{t+1, w}>0$, under the same inequalities (20) on relative prudence, if the relative degree of aversion to effort is small at the deterministic steady state, $R_{V}\left(x^{*}\right)=$ $x^{*} V^{\prime \prime}\left(x^{*}\right) / V^{\prime}\left(x^{*}\right)<1$. It is countercyclical, $d \bar{c}_{t+1, w}<0$, if aversion to effort is large, $R_{V}\left(x^{*}\right)>1$, and relative prudence does not decrease too fast, $P_{U}(c)-2<\varepsilon_{P_{U}}(c) \leq 0$, on an interval $\left(\gamma_{1}, \gamma_{2}\right)$ for consumption including $c^{*}$ and $\nu c^{*}$.

The detailed proof rests on a straightforward differenciation of (18), (19), and is given in the appendix. It is useful to illustrate intuitively here, without getting into details, the role and meaning of the assumptions made on relative 
prudence for the behavior of the workers' expected utility gain of not shirking $\varphi(c)=\theta[U(c)-U(\nu c)]$. As already noted in assumption (2.e), a low relative prudence $P_{U}(c)<2$ means that $-c^{2} U^{\prime \prime}(c)$ is increasing. As this prevails over an interval $\left(\gamma_{1}, \gamma_{2}\right)$ that includes the steady state consumptions $c^{*}$ and $\nu c^{*}$, this implies that $c^{2} \varphi^{\prime \prime}(c)=\theta\left[c^{2} U^{\prime \prime}(c)-\nu^{2} c^{2} U^{\prime \prime}(\nu c)\right]$ is negative at $c=c^{*}$, and that it gets larger in absolute value when $P_{U}(c)$ gets smaller on that interval $\left(\gamma_{1}, \gamma_{2}\right)$. The elasticity of relative prudence has similar consequences on the sign and magnitude of $c^{3} \varphi^{\prime \prime \prime}(c)=\theta\left[c^{3} U^{\prime \prime \prime}(c)-\nu^{3} c^{3} U^{\prime \prime \prime}(\nu c)\right]$ at $c^{*}$. The elasticity of $c^{3} U^{\prime \prime \prime}(c)$ is equal to $2-P_{U}(c)+\varepsilon_{P_{U}}$. So a fast decreasing relative prudence as in $(20)$ on an interval $\left(\gamma_{1}, \gamma_{2}\right)$ ensures that $c^{3} U^{\prime \prime \prime}(c)$ is decreasing fast on that interval. In that case, if $\left(\gamma_{1}, \gamma_{2}\right)$ includes $c^{*}$ and $\nu c^{*}$, $c^{3} \varphi^{\prime \prime \prime}(c)$ is also negative at $c^{*}$, and gets larger in absolute value when $\varepsilon_{P_{U}}(c)<$ $P_{U}(c)-2<0$ gets more and more negative over $\left(\gamma_{1}, \gamma_{2}\right)$. Analytically, the coefficients of the anticipated variance $v_{\varepsilon}$ of the future consumption sunspot shock $\varepsilon_{t+1}$ in (18), (19) become more and more negative, which ensures that $d x_{t}>0$ when $d v_{t+1}<0$.

On the economic side, current effort may be viewed as some sort of costly "precautionary saving" that seeks to guarantee the expected mean consumption $\bar{c}_{t+1, w}$, while coping with the risk involved in the future sunspot consumption shock $\varepsilon_{t+1}$. A lower relative prudence $P_{U}(c)<2$ means that the expected utility gain of not shirking $\varphi(c)$ is more concave (displays more risk aversion). This implies that a decrease in the risk of the anticipated sunspot shock makes workers more willing to provide the requested "precautionary effort" : the expected utility gain of not shirking in the NSS (16) gets larger for a given expected mean reward $\bar{c}_{t+1, w}$ (the curve representing the NSS (16) goes up in Fig.1). On the other hand, making relative prudence to decrease faster (its elasticity $\varepsilon_{P_{U}}(c)$ more negative) diminishes $\varphi^{\prime \prime \prime}(c)$, i.e. makes the decreasing "marginal expected utility of not shirking" $\varphi^{\prime}(c)>0$, in (17) or in (9), "more concave", i.e. to display "less prudence". So this should also make workers more willing at the margin to provide the requested "precautionary effort" following a decrease in the risk of the future sunspot shock $\varepsilon_{t+1}$. For in such a case, the marginal expected utility of not shirking in (17) reacts more positively to a risk decrease, given expected mean consumption $\bar{c}_{t+1, w}$. What Proposition 4 states is that when relative prudence is low and decreases fast as in $(20)$, over an interval of consumptions $\left(\gamma_{1}, \gamma_{2}\right)$ containing $c^{*}$ and $\nu c^{*}$, these two combined effects imply that $d v_{t+1}<0$ leads to $d x_{t}>0$.

We end up with an application to the analytical specification where the 
workers' utility for consumption displays Hyperbolic Absolute Risk Aversion (HARA), i.e.

$$
U(c)=(c-a)^{1-\eta} /(1-\eta) \text { and } A_{U}(c)=-U^{\prime \prime}(c) / U^{\prime}(c)=\eta /(c-a),
$$

on the consumption interval $\left(\gamma_{1}, \gamma_{2}\right)$ containing the steady state consumptions $c^{*}$ and $\nu c^{*}$ as in Proposition 4. As Lemma 2 established that effort was constant, $x_{t}=x^{*}$, in the CRRA specification $a=0$, we focus here on the case where $a>0$. It is then immediate to verify by direct inspection :

Corollary 2. Let $\left(\gamma_{1}, \gamma_{2}\right)$ be an interval containing the workers' steady state consumptions, $0<\gamma_{1}<\nu c^{*}<c^{*}<\gamma_{2}$. Assume that the workers' utility for consumption is of the HARA family, $U(c)=(c-a)^{1-\eta} /(1-\eta)$ on that interval, with $0<\eta<1$ and $\gamma_{1}>a>0$. Then

i) assumption (2.c), i.e. $R_{U}(c)<1$, is met on $\left(\gamma_{1}, \gamma_{2}\right)$ if and only if $(1-\eta) \gamma_{1}>a$.

ii) assumption (2.e), i.e. $P_{U}(c)<2$, is met on $\left(\gamma_{1}, \gamma_{2}\right)$ if and only if $(1-\eta) \gamma_{1}>2 a$.

iii) condition (20), i.e. $\varepsilon_{P_{U}}(c)<P_{U}(c)-2$, is met on $\left(\gamma_{1}, \gamma_{2}\right)$ if and only if $(1-\eta) \gamma_{2}<3 a$.

\section{Conclusion}

As noted in the introduction, the basic initial motivation behind the introduction of exogenous technology shocks in Real Business Cycles (RBC) macroeconomic models was their potential to generate more or less pronounced comovements of labor productivity, output, employment, real wages. Beyond the issue of evaluating whether this research avenue was empirically fully successful (see e.g. Francis et al. (2005), Gali (1999)), this work considers an alternative theoretical mechanism that would rely instead on endogenous procyclical variations of workers' effort. The novelty of the proposed mechanism is to mix two approaches that have been studied only separately in the literature. Namely, 1) the occurrence of persistent structural unemployment through efficiency wage contracting arguments of the "no-shirking" variety, and 2) the generation of endogenous expectations driven business cycles through stochastic sunspot (consumption) shocks near a locally indeterminate steady state. Workers' non-shirking schedule reflects the equality 
of their disutility of effort with their expected utility gain of not shirking, measured in terms of the resulting anticipated random consumption they can obtain from the real income they get. If there is conditional heteroskedasticity of sunspot consumption shocks, so that a current positive sunspot shock generates a decrease of the anticipated sunspot consumption volatility, risk averse workers are more willing to provide "precautionary effort" for a given real wage. We show further that if workers' relative prudence is less than 2 and decreasing fast near the steady state, the efficiency wage contracts chosen by firms do induce then workers to provide more effort, so that it can display significant procyclical movements that are potentially useful to match empirical regularities without having to appeal to exogenous shocks to fundamentals. Even though the voluntarily (over)simplified structure of the model does not make it quite fit to fullfledged empirical investigations, the proposed real mechanism linking conditionally heteroskedastic sunspot shocks to procyclical effort movements appears to be quite plausible in terms of workers' behavior. Such conditional heteroskedasticity of uncertainty shocks have been found to be quite relevant in financial analysis and the study of asset returns (Nelson (1991), Francq et al. (2010). Moreover, potential links between such conditionally heteroskedastic shocks and related stochastic properties of consumption, or countercyclical macroeconomic uncertainty shocks, have received recent increasing attention (Boguth et al. (2013), Bloom et al. (2014), Tedongap (2016), Wang (2006)). The real mechanism presented here appears accordingly to be a potentially fruitful avenue to investigate further. 


\section{Appendix}

Proof of Proposition 4

Differenciation of (18), (19) with respect to $x=x_{t}, c=\bar{c}_{t+1, w}, v_{\varepsilon}=$ $E_{t}\left[\left(\varepsilon_{t+1}\right)^{2}\right]$ yields, after neglecting 3rd order terms such as $v_{\varepsilon} d c$,

$$
\begin{aligned}
V^{\prime} d x & \simeq \varphi^{\prime} d c+\frac{1}{2} c^{2} \varphi^{\prime \prime} d v_{\varepsilon} \\
\left(V^{\prime}+x V^{\prime \prime}\right) d x & \simeq\left(\varphi^{\prime}+c \varphi^{\prime \prime}\right) d c+\left(c^{2} \varphi^{\prime \prime}+\frac{1}{2} c^{3} \varphi^{\prime \prime \prime}\right) d v_{\varepsilon}
\end{aligned}
$$

which can be solved into

$$
\begin{aligned}
\left(V^{\prime} c \varphi^{\prime \prime}-x V^{\prime \prime} \varphi^{\prime}\right) d x & \simeq \frac{1}{2}\left[c^{3}\left(\varphi^{\prime \prime}\right)^{2}-c^{2} \varphi^{\prime \prime} \varphi^{\prime}-c^{3} \varphi^{\prime \prime \prime} \varphi^{\prime}\right] d v_{\varepsilon} \\
\left(\frac{x V^{\prime \prime}}{V^{\prime}} \varphi^{\prime}-c \varphi^{\prime \prime}\right) d c & \simeq \frac{1}{2}\left[c^{2} \varphi^{\prime \prime}\left(1-\frac{x V^{\prime \prime}}{V^{\prime}}\right)+\frac{1}{2} c^{3} \varphi^{\prime \prime \prime}\right] d v_{\varepsilon} .
\end{aligned}
$$

In the above, again up to 3rd order terms, all these expressions can be evaluated at the deterministic steady state values $x=x^{*}, c=c^{*}$. From assumption $(2 . b)$, the disutility of effort is increasing and convex, $V^{\prime}>0, V^{\prime \prime}>0$, while from assumption (2.e), $c^{2} \varphi^{\prime \prime}(c)=\theta\left[c^{2} U^{\prime \prime}(c)-\nu^{2} c^{2} U^{\prime \prime}(\nu c)\right]<0$ at $c=c^{*}$ if $-c^{2} U^{\prime \prime}(c)$ is increasing, or $P_{U}(c)<2$, over an interval $\left(\gamma_{1}, \gamma_{2}\right)$ containing $c^{*}$ and $\nu c^{*}$. In order to get $d x / d v_{\varepsilon}<0$, hence $d x_{t} / d \varepsilon_{t}>0$ under assumption $(3 . b)$, it is therefore sufficient that

$$
c^{3} \varphi^{\prime \prime \prime}(c)=\theta\left[c^{3} U^{\prime \prime \prime}(c)-\nu^{3} c^{3} U^{\prime \prime \prime}(\nu c)\right]<0 \text { at } c=c^{*} .
$$

A sufficient condition is that $c^{3} U^{\prime \prime \prime}(c)$ be decreasing in the interval $\left(\gamma_{1}, \gamma_{2}\right)$. The elasticity of $c^{3} U^{\prime \prime \prime}(c)=-c^{2} P_{U}(c) U^{\prime \prime}(c)$ is $2+\varepsilon_{P_{U}}(c)-P_{U}(c)$, so the inequalities (20) over $\left(\gamma_{1}, \gamma_{2}\right)$ are indeed sufficient for $d x_{t} / d \varepsilon_{t}>0$. The derivative $d x_{t} / d v_{t+1}<0$ will be larger in absolute value whenever $-c^{2} U^{\prime \prime}(c)$ and $c^{3} U^{\prime \prime \prime}(c)$ increase more strongly, hence whenever the inequalities in (20) are larger, over the range $\left(\gamma_{1}, \gamma_{2}\right)$.

Similarly, one will get $d c / d v_{\varepsilon}<0$, hence $d \bar{c}_{t+1, w} / d \varepsilon_{t}>0$ under assumption (3.b), if $c^{3} \varphi^{\prime \prime \prime}(c)<0$ at the steady state $c^{*}$, i.e. under the same inequalities $(20)$ over $\left(\gamma_{1}, \gamma_{2}\right)$, provided that $R_{V}\left(x^{*}\right)<1$. By contrast, one will get 
$d c / d v_{\varepsilon}>0$ if $R_{V}\left(x^{*}\right)>1$ and if $c^{3} \varphi^{\prime \prime \prime}(c)>0$ at $c=c^{*}$. A sufficient condition for that is that $c^{3} U^{\prime \prime \prime}(c)$ is increasing, i.e. $P_{U}(c)-2<\varepsilon_{P_{U}}(c) \leq 0$ over the interval $\left(\gamma_{1}, \gamma_{2}\right)$ containing $c^{*}$ and $\nu c^{*}$. 


\section{References}

[1] Alexopoulos, M. (2004), "Unemployment and the business cycle", Journal of Monetary Economics, 51, 277-98.

[2] Aloi, M. and Lloyd-Braga, T. (2010), "National labor markets, international factor mobility and macroeconomic instability", Economic Theory, $43(3), 431-56$.

[3] Basu, S. and Fernald, J. (2001), "Why is productivity procyclical ? Why do we care ?", in New Developments in Productivity Analysis, Hulten, C.R., Dean, E.R. and Harper, M.J. (eds.), NBER, 225-302.

[4] Bewley, T.F. (1999), Why Wages don't Fall during a Recession, Harvard University Press, Cambridge.

[5] Bils, M. and Chang, Y. (2001), "Cyclical movements of hours and effort under sticky wages", International Economic Journal, 15 (2), 1-26.

[6] Bloom, N., Floetotto, M., Jaimovich, N., Saporta-Eksten, I. and Terry, S.J. (2014), "Really Uncertain Business Cycles", Discussion paper, U.S. Census Bureau, Center for Economic Studies.

[7] Boguth, O. and Kueln, L. -A. (2013), "Consumption volatility risk", The Journal of Finance, 68 (6), 2589-2615.

[8] Campbell, C.M. III and Kamlani, K.S. (1997), "The reasons for wage rigidity : evidence from a survey of firms", The Quarterly Journal of Economics, 112 (3), 759-789.

[9] Chirinko, R.S. (2008), " $\sigma$ : the long and short of it", Journal of Macroeconomics, 30, 671-86.

[10] Coimbra, R. (1999), "Efficiency Wages, Increasing Returns and Endogenous Fluctuations", Working Paper 1999-06, University of York.

[11] Collard, F. and de la Croix, D. (2000), "Gift exchange and the business cycle : the fair wage strikes back", Review of Economic Dynamics, 3, 166-93.

[12] Danthine, J.-P. and Donaldson, J.B. (1990), "Efficiency wages and the business cycle puzzle", European Economic Review, 34, 1275-1301. 
[13] Danthine, J.-P. and Kurmann, A. (2006), "Efficiency wage revisited : the internal reference perspective", Economics Letters, 90, 278-84.

[14] Dos Santos Ferreira, R., Lloyd-Braga, T. and Modesto, L. (2015), "The destabilizing effects of the social norm to work under a social security system", Mathematical Social Sciences, 76, 64-72.

[15] Dufourt, F., Lloyd-Braga, T. and Modesto, L. (2008), "Indeterminacy, bifurcations and unemployment fluctuations", Macroeconomic Dynamics, 12, $75-89$.

[16] Dufourt, F., Lloyd-Braga, T. and Modesto, L. (2009), "Expected Inflation, Sunspots Equilibria and Persistent Unemployment Fluctuations", IZA Discussion paper 4302.

[17] Dufourt, F., Lloyd-Braga, T. and Modesto, L. (2013), "Sunspot Equilibria and the Expectation-Driven Phillips Curve", Working paper, GREQAM, Aix-Marseille University.

[18] Francis, N. and Ramey, V.A. (2005), "Is the technology-driven real business cycle hypothesis dead? Shocks and aggregate fluctuations, revisited", Journal of Monetary Economics, 52, 1379-99.

[19] Francq, C. and Zakoïan, J.-M. (2010), "Inconsistency of the MLE and inference based on weighted LS in LARCH models", Journal of Econometrics, 159, 151-65.

[20] Gali, J. (1999), "Technology, employment, and the business cycle : do technology shocks explain aggregate fluctuations ?", American Economic Review, 89, 249-71.

[21] Grandmont, J.-M. (2008), "Negishi-Solow efficiency wages, unemployment insurance and dynamic deterministic indeterminacy", International Journal of Economic Theory, 80, 14-59.

[22] Grandmont, J.-M., Pintus, P.A. and de Vilder, R. (1998), "Capitallabor substitution and competitive nonlinear endogenous business cycles", Journal of Economic Theory, 80, 14-59.

[23] Hall, R.E. (1978), "Stochastic implications of the life cycle-permanent income hypothesis : theory and evidence", Journal of Political Economy, 86 (6), 971-87. 
[24] Kimball, M.S. (1990), "Precautionary saving in the small and in the large", Econometrica, 58, 53-73.

[25] Jullien, B. and Picard, P. (1998), " A classical model of unvoluntary unemployment : efficiency wages and economic policy", Journal of Economic Theory, 78, 263-85.

[26] Leland, H.E. (1968), "Saving and uncertainty : the precautionary demand for saving", Quarterly Journal of Economics, 82, 465-73.

[27] Messina, J., Strozzi, C. and Turunen, J. (2009), "Real wages and the business cycle : OECD evidence from the time and frequency domains", Journal of Economic Dynamics and Control, 33 (6), 1183-1200.

[28] Nakajima, T. (2006), "Unemployment and indeterminacy", Journal of Economic Theory, 126, 314-27.

[29] Negishi, T. (1979), Microeconomic Foundations of Keynesian Macroeconomics, North-Holland.

[30] Nelson, D.B. (1991), "Conditional heteroskedasticity in asset returns : a new approach", Econometrica, 59 (2), 347-70.

[31] Rothschild, M. and Stiglitz, J. (1970), "Increasing risk I : a definition", Journal of Economic Theory, 2, 225-43.

[32] Shapiro, C. and Stiglitz, J. (1994), "Equilibrium unemployment as a worker discipline device", American Economic Review, 74, 433-44.

[33] Solon, G., Barsky, R. and Parker, J.A. (1994), "Measuring the cyclicality of real wages : how important is composition bias ?", Quarterly Journal of Economics, 109 (1), 1-25.

[34] Solow, R.M. (1979), "Another possible source of wage stickiness", Journal of Macroeconomics, 1, 79-82.

[35] Stiglitz, J. (1986), "Theories of wage rigidities", in Keynes' Economic Legacy : Contemporary Economic Theories, Butkiewicz, J.L. et al. (eds.), New York, Praeger Publishers, pp. 153-206.

[36] Tedongap, R. (2015), "Consumption volatility and the cross-section of stock returns", Review of Finance, 19 (1), 367-405. 
[37] Uhlig, H. (2004), "Do technology shocks lead to a fall in total hours worked ?" Journal of the European Association, 2 (2-3), 361-71.

[38] Uhlig, H. and Xu, Y. (1996), "Effort and the Cycle : Cyclical Implications of Efficiency Wages", Working paper, 1996-49, CentER, Tilburg University.

[39] Verdugo, F. (2016), "Real wage cyclicality in the eurozone before and during the Great Recession : evidence from microdata", European Economic Review, 82, 46-69.

[40] Wang, N. (2006), "Generalizing the permanent-income hypothesis : revisiting Friedman's conjecture on consumption", Journal of Monetary Economics, 53, 737-52.

[41] Woodford, M. (1986), "Stationary sunspot equilibria in a finance constrained economy", Journal of Economy Theory, 40, 128-37.

[42] Yellen, J.L. (1984), "Efficiency wages models of unemployment", American Economic Review (Papers and proceedings), 74, 200-205. 


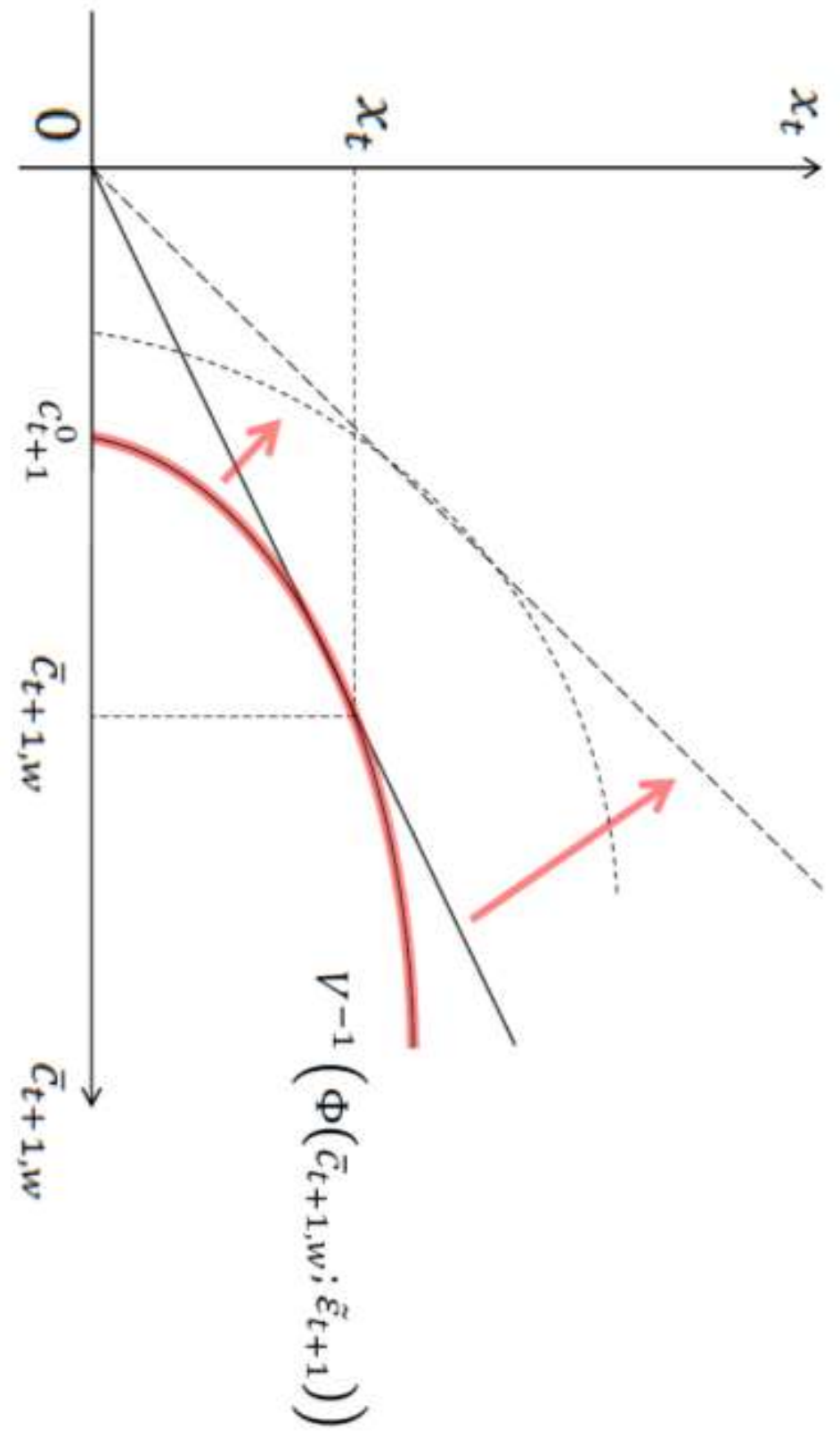

